\title{
Hemangioma capilar lobular nasal. A propósito de un caso
}

\author{
Nasal lobular capillary hemangioma: A case report \\ Ray Salazar-Minaya ${ }^{1, a ; 2, b}$, Gino Boero-Zunino ${ }^{1, a, c}$

\section{RESUMEN}

Se presenta el caso de una mujer de 36 años, primigesta, quien en el cuarto mes de gestación presentó una lesión en la zona vestibular nasal derecha, secundaria a rinorrea acuosa por rinitis aguda viral; debido a la manipulación continua, la lesión sufría erosiones recurrentes y con el tiempo desarrolló una tumoración que creció hasta protruir hacia el exterior. La extirpación se realizó dos meses después del parto, y el estudio anátomo-patológico reveló hemangioma capilar lobular. Debido a que el lugar de presentación es inusual se reporta el caso y se realizó una revisión del tema.

PALABRAS CLAVE: Granuloma, granuloma piogénico, cavidad nasal. (Fuente: DeCS BIREME).

\section{SUMMARY}

We present the case of a 36-year-old woman who developed during the fourth month of her first pregnancy a lesion of the right nose following an acute viral rhinitis. Due to constant manipulation and recurrent erosions the lesion evolved to a tumor that protruded the nostril and obstructed the airway. The lesion was removed two months after delivery and the pathological diagnosis revealed a nasal lobular capillary hemangioma. Due to the rare presentation of this entity, we performed a literature review.

KEYWORDS: Granuloma, pyogenic granuloma, nasal cavity. (Source: MeSH NLM).

\section{INTRODUCCIÓN}

El hemangioma capilar lobular es una lesión benigna que se produce por una proliferación vascular reactiva a diferentes estímulos, especialmente traumáticos de heridas (1).

Se presenta como una lesión única, pediculada y asintomática cubierta por una capa epitelial lisa de color rojizo (por su componente vascular) y cubierto por una costra, se ubica frecuentemente en las manos y mucosa gingival, aunque puede aparecer en cualquier sitio (1). Clásicamente es muy vascularizada y sangra con facilidad (2).
En 1879, Rivolta describió por primera vez esta lesión. En 1887, Bollinger propuso que era causado por un parásito que denominó Botryomyces. En 1897, Poncet y Dor publicaron cuatro pacientes con neoformaciones vasculares y las llamaron Botryomycosis hominis relacionándolos al contagio de caballos con micosis, por lo que llamaron a la lesión, botriomicosis humana. En 1904, Hartzell propuso el término granuloma piógeno y Küttner sugirió el nombre de granuloma telangiectásico. También se le ha denominado hemangioma eruptivo, hemangioma capilar lobular y granuloma telangiectásico (3).

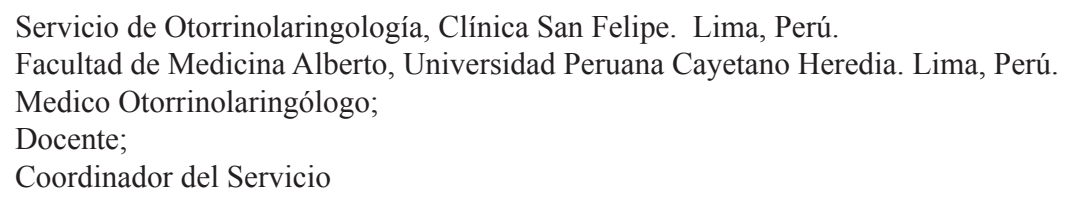


El término granuloma piógeno es inadecuado, ya que no está constituido por infiltrado granulomatoso y no es un padecimiento microbiano (4-6). Actualmente se ha llegado al consenso que es una lesión reactiva a una injuria de tipo repetitiva sea en piel o mucosas, siendo la boca y las manos los lugares más comunes de aparición (7-8); por ello, actualmente se le prefiere denominar hemangioma capilar lobular.

Se debe mencionar que los cambios hormonales producidos en la gestación, en la pubertad, en la anticoncepción oral, $\mathrm{y}$ en la terapia de reemplazos hormonales, pueden ser factores de riesgo para la aparición de estas lesiones, debido que en esas situaciones se presenta con mayor frecuencia (9-10).

Es importante mencionar que el hemangioma capilar lobular se presenta en todas partes del cuerpo, siendo los miembros superiores, los lugares más comunes. En segundo lugar, está la cara en $28 \%$, tanto intraorales como extraorales. Algunos autores mencionan una prevalencia de alrededor de $5 \%$ en la población gestante, en especial entre el segundo y tercer trimestre $(9,11)$.

Se reporta este caso debido a la presentación poco común en el vestíbulo nasal y se realizó una revisión respecto al tema.

\section{PRESENTACIÓN DEL CASO}

Mujer de 36 años de edad, primigesta, quien en el cuarto mes de gestación presentó una lesión en la zona vestibular nasal derecha, que se originó después de un cuadro de rinorrea acuosa secundaria a rinitis aguda de tipo viral. Debido a la manipulación continua, la lesión sufría erosiones, reapareciendo en varias oportunidades. Con el tiempo se generó una lesión tumoral que creció progresivamente, llegando a protruir al exterior. La sintomatología se caracterizaba por sangrados leves repetitivos y obstrucción de dicha fosa nasal.

La paciente acudió al consultorio de otorrinolaringología al término de la gestación. Al examen, se observó una lesión de $1 \mathrm{~cm}$ de diámetro, lisa, con costra en su superficie que se inserta en zona superior y medial del vestíbulo nasal derecho (figura $1)$.

La extracción de la lesión por disección fría, se decidió a los 2 meses de terminado la gestación, Se le indicó prednisona $20 \mathrm{mg}$ cada 12 horas por 5 días

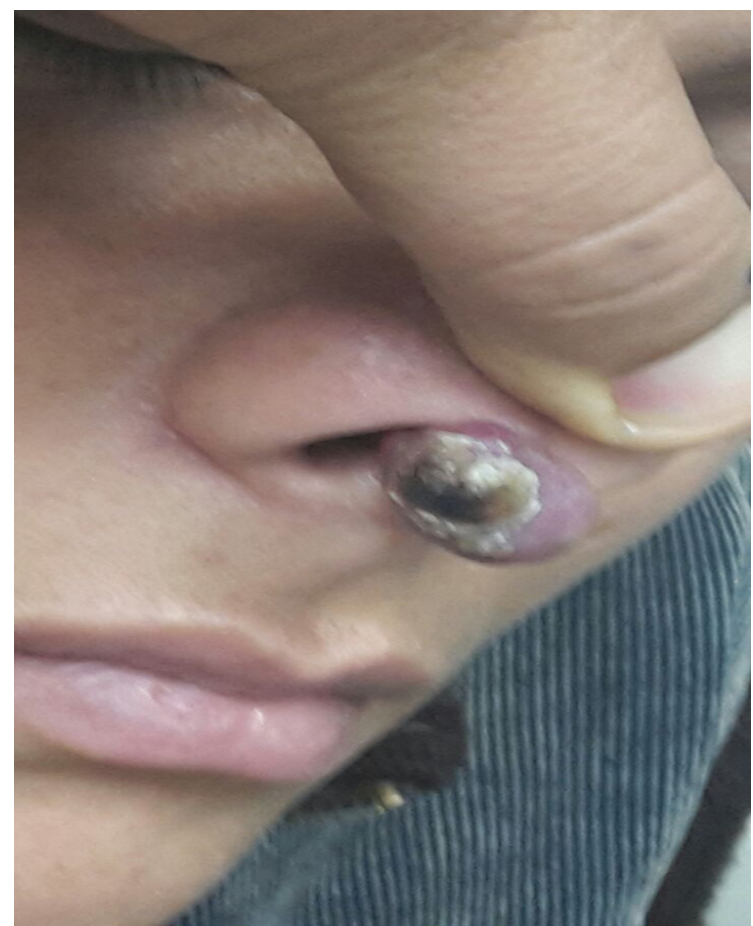

Figura 1. Tumoración en vestíbulo nasal.

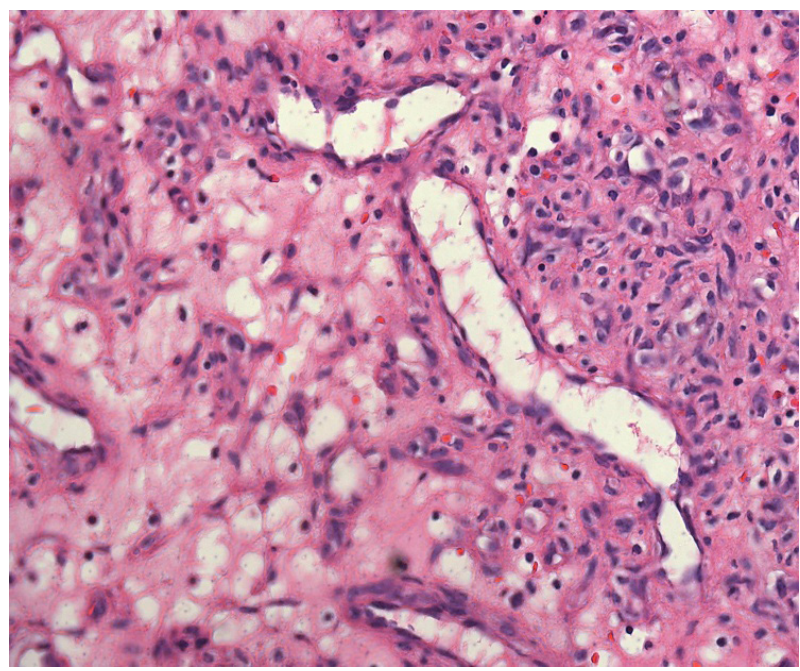

Figura 2. Estudio patológico realizado: Hemangioma capilar lobular de vestíbulo. Se describe como una extensa proliferación endotelial con espacios vasculares prominentes y dispuestos en lóbulos, separados por septos de tejido fibroconectivo formado por haces de colágeno, fibroblastos estrellados y algunos mastocitos.

y cefalexina $500 \mathrm{mg}$ cada 8 horas por 7 días, una semana previa a la intervención. El sangrado durante la intervención fue leve. El lecho operatorio fue cauterizado. Se colocó taponamiento con mechas de gasa en el vestíbulo derecho, el cual fue retirado a los 
tres días. El resultado de la anatomía patológica fue Hemangioma capilar lobular. (figura 2).

La evolución de la paciente después de dos años de la intervención ha sido favorable sin recidiva ni complicaciones.

\section{DISCUSIÓN}

El hemangioma capilar lobular es una tumoración benigna y de crecimiento rápido; predomina en mujeres en una relación de 3 a 2 (12).

La presentación en la cara ocurre hasta en $28 \%$ de todos los casos, siendo la cavidad oral y los labios la ubicación más común. (9) La presentación nasal, según varios reportes, no es frecuente, pero cuando se presenta se da en la pared septal en la zona del plexo de Kiesselbach (13), en 71\% de los casos, seguido del cornete inferior, piso nasal, cornete medio, etc (9). La afectación nasal vestibular es muy rara.

Esta entidad se presenta con mayor frecuencia entre 11 a 40 años de edad, pero se ha visto casos desde los seis días de nacido hasta en personas de edad avanzada.

Las características de nuestra paciente coinciden con los datos epidemiológicos frecuentes, como el sexo femenino, manipulación continua de la lesión y el de haber estado gestando.

Se debe mencionar que en el embarazo se incrementan los niveles de progesterona, produciéndose una dilatación y proliferación de la microvasculatura en la piel y mucosas, facilitando el desarrollo de la lesión (10).

Según algunos autores, los síntomas más comunes son la epistaxis, en alrededor del $92 \%$, y protrusión de la lesión hacia el exterior produciendo obstrucción nasal, no encontrándose molestias de dolor $(14,15)$. Nuestro caso presentó epistaxis y obstrucción como principales molestias.

Como exámenes auxiliares se recomienda tomografía de senos paranasales cuando existe afectación de la fosa nasal. En gestantes el estudio de imágenes a considerar seria la resonancia magnética nuclear si fuera necesario $(15,16)$.

En el diagnóstico diferencial se debe tener en cuenta el granuloma periférico de células gigantes, sarcoma de Kapossi, melanoma, fibroma, carcinomas, etc (17).

El tratamiento recomendado es el quirúrgico y en caso de estar gestando, se debe esperar el término de la misma. En el caso que se presenta, la intervención se realizó dos meses después del parto. Los cambios hormonales post parto disminuyen el tamaño de la tumoración y el sangrado, lo que permite mejores resultados en el tratamiento quirúrgico y reduciendo las recidivas (17).

Se menciona que el uso de corticoides y antibióticos preoperatorios, podría disminuir el tamaño y el sangrado operatorio (18), en el caso reportado se realizó una semana antes de la intervención.

En el acto operatorio se debe manejar adecuadamente la zona de implantación de la lesión para evitar la recidiva. En nuestro caso, aparte de la resección se realizó la cauterización del lecho de acuerdo a lo que se recomienda en la literatura, teniendo cuidado el evitar lesionar el cartílago alar para evitar su necrosis, la evolución fue adecuado, sin recidiva luego de 2 años de la intervención.

En conclusión, esta entidad se debe tener en cuenta para el diagnóstico diferencial de tumores vestibulares nasales en especial en gestantes. Su tratamiento es quirúrgico, teniendo evolución favorable.

\section{Declaración de financiamiento y de conflictos de intereses:}

El reporte fue financiado en su integridad por los investigadores, quienes declaran no tener conflictos de intereses

\section{Contribución de autoría:}

RS; GB: Participaron en la redacción del reporte, revisión bibliográfica y aprobación de la versión a ser publicada.

\section{Correspondencia:}

Dr. Ray Salazar

Correo electrónico: ray@planet.com.pe

\section{REFERENCIAS BIBLIOGRÁFICAS}

1. Moreno A, Bordas X, Joule A. Granuloma Piógeno. En: Moreno A, Requena L, Rodríguez JL. editores. 
Dermatopatologia correlación clínica patológica. Madrid: Área científica Menarini; 2007. p. 251-254.

2. Sanabria A, Varela G. Granuloma piógeno como diagnóstico diferencial de las masas del vestíbulo nasal. Reporte de caso. Acta de Otorrinolaringología y Cirugía de Cabeza y Cuello. 2013; 41(2):142-146.

3. Vences M, Novales J, Martínez V, Medina A. Granuloma piógeno. Correlación clínico-patológica. Dermatología Rev Mex. 2005; 49:101-8.

4. Cordero A, Araya H. Granuloma piógeno (hemangioma Lobular Capilar) importancia de una remoción completa en el granuloma piógeno. Rev Cient Odontol. 2009; 5(1):17-21.

5. Regezi JA, Sciubba J. Patología bucal. Tercera edición. México: Interamericana Mc Graw; 2007.

6. García I, Hinojosa A, Aldape B, Valenzuela E. Hemangioma lobular capilar (granuloma piógeno) asociado a la erupción: Reporte de dos casos clínicos. Rev Odontol Mex. 2004; 8 (4):127-132.

7. Leyden J, Master G. Oral cavity piogenic granuloma. Arch Dermatol. 1973; 108:226-228.

8. Patrice S, Wiss K, Mulliken J. Pyogenic granuloma (lobular capillary hemangioma) a clinicopathologic study of 178 cases. Pediatric Dermatol. 1991; 8:267276.

9. Lopez A, Tang S, Kacker A, Scognamiglio T. Demographics and etiologic factors of nasal pyogenic granuloma. Int Forum Allergy Rhinol. 2016; 20:1-4.

10. Sanchez J, Villaroel M, Lopez-Labady J, Mata De Henning M. Granuloma piogeno: Reporte de un caso. Acta odontológica Venezolana. 2000; 38(2):36-40.

11. Diaz-Guzman LM, Castellanos-Suarez JL. Lesiones de la mucosa bucal y comportamiento de la enfermedad periodontal en embarazadas. Med Oral Patol Oral Cir Bucal. 2004; 9:430-7.
12. Bhaskar G, Jacoway J. Pyogenic granuloma. Clinical Features, incidence, histology and retreatment: report of 242 cases. Oral Surg. 1966; 24:391-398

13. Karagama YG, Howarth K, Steel PRM, Spencer MG. Lobular Capillary Haemangioma of the nasal vestibule: a rare entity. Int J.Pediatr Otorhinolaryngol. 2002; 66:71-75.

14. Nayac DR, Bhandarkar AM, Shivamurthy A, Joy J. Intranasal Lobular capillary Haemangioma. BMJ Case Reports. 10 de octubre del 2014; Published online. doi:10.1136/bcr-2014-207196

15. Patil P, Singla S,Mane R,Jagdeesh K. Nasal lobular capillary hemangioma. J Clin Imaging Sci. 2013; 3:40. doi: 10.4103/2156-7514.119134

16. Oakes RE, Frampton S, Scott P. Granuloma gravidarum: Management. Journal of Obstetrics and Gynaecology.2014; 32:805.

17. Delbrouck C,Chamiec M, Hassid S, Ghanooni R. Lobular capillary Haemangioma of the nasal cavity during pregnancy. The Journal of Laryngology \& Otology. 2011; 125:973-977.

18. Hanazawa T, Yonekura S, Nakamura H, Fujikawa A, Okamoto Y.Pre-operative effects of the administration of systemic corticosteroids combined with antibiotics on a lobular capillary hemangioma in the nasal cavity. Auris Nasus Larynx. 2016; 43(2):203-6. doi: 10.1016/j.anl.2015.08.001

Recibido: $22 / 11 / 2017$

Aceptado: 20/12/2018 